Marcela Arpes *

Universidad Nacional de la Patagonia Austral, Argentina

\section{Archivo y documentalismo en la escena argentina. Campo minado de Lola Arias como experiencia de teatro documental}

\author{
Archive and documentalist in the Argentinian scene. Campo \\ Minado by Lola Arias as a documentary experience of drama
}

Resumen

Dentro de los estudios teatrales la categoría teórica denominada «teatro documento» (Weiss [1968] 2017; Verzero, 2017; Pavis, 1998) es una de las formas dramáticas contemporáneas menos indagadas. Habitualmente el estudio del teatro documento se inscribe dentro de una noción más general llamada «teatro político» (Piscator, 1976; Brecht [1948] 1983; Badiou, 2005; Pavis, 1998; Irazabal, 2004). Si bien puede considerarse que todo teatro en sí mismo es político, sin embargo, la noción teórica formulada por Erwin Piscator data de las primeras décadas del siglo XX. Piscator trasladó la teoría marxista al teatro y recogió sus ideas y experiencias en su libro Teatro Político publicado en 1929, allí el autor dedica todo un capítulo a las obras documentales, las cuales liga indefectiblemente a la filosofía del materialismo histórico. El teatro documento o documental puede considerarse un deslinde o una deriva de esta noción, al crearse en el linde entre la ficción y la realidad y trabajar especialmente con las ideas de archivo y documento o fuente primaria. Es también en Alemania donde se logra formalizar esta experiencia creativa sobre todo a partir del teatro y las ideas teóricas de Peter Weiss (1968). El teatro documento se enfrenta a la clásica definición de teatro dramático, confundido muchas veces con la denominación de docudrama, teatro histórico o biodrama, el teatro documental pretende no ser ficcional y además estar protagonizado por los propios involucrados en el acontecimiento que se teatraliza. Es decir, el valor documental radica en la apropiación de una historia real, en la activación semiótica de insumos teatrales (textos, fotos, proyecciones, vestuario, objetos, testimonios) que provienen de ese acontecimiento de la realidad y, además, en que es actuado por personas involucradas en ese hecho. En la Argentina, quien se siente y se reconoce inscripta en el linaje del teatro alemán de siglo XX y especialmente del de Weiss es la escritora, directora de teatro y cine y performer Lola Arias. En el presente artículo, analizaremos la presencia del teatro documental en su obra, pero especialmente en Campo minado (2016-2020), obra que reúne en escena a tres veteranos argentinos y a tres marines ingleses para narrar y documentar la experiencia y los efectos traumáticos de la guerra de Malvinas.

Palabras clave

teatro político, teatro documental, Lola Arias, campo minado.

\footnotetext{
* Marcela Arpes es Doctora en Letras por la Universidad de Buenos Aires. Profesora Asociada Ordinaria de la Escuela de Letras de la Unidad Académica Río Gallegos de la Universidad Nacional de la Patagonia Austral donde dicta las cátedras de Literatura Argentina I y II. Es investigadora del Instituto de Investigación y Extensión Identidad, Cultura y Comunicación (ICIC). Sus estudios de doctorado y posdoctorado se centran en los estudios teatrales y dramatúrgicos argentinos.
} 


\begin{abstract}
In drama studies, the theoretical category 'documentary theatre' (Weiss,[1968] 2017; Verzero, 2017; Pavis, 1998) is one of the least studied contemporary dramatic forms. Usually, the study of document drama is included within the more general notion of 'political theater' (Piscator, 1976) Brecht,[1948] 1983; Badiou, 2005; Pavis, 1998; Irazabal, 2004). All theater can be considered political, however, the theoretical notion formulated by Erwin Piscator dates back to the first decades of the XX century. Piscator used Marxist theory to analyse theater and collected his ideas and experiences in his book Political Theatre, published in 1929, where the author devotes an entire chapter to documentary plays, which he links unfailingly to the philosophy of historical materialism. Documentary theatre can be considered a demarcation or a derivation of this notion, as it is created on the borderline between fiction and reality and works especially with the ideas of archive and document or primary source. It is also in Germany where this creative experience is formalized, especially from Peter Weiss's theater and theoretical ideas (1968). Documentary theatre confronts the classic definition of dramatic theatre, often confused with the denomination of docudrama, historical drama, or biodrama, documentary theater pretends not to be fictional and to be starred by those actually involved in the real event being staged. That is to say, the documentary value lies in the appropriation of a real story, the semiotic activation of theatrical inputs (texts, photos, screenings, costumes, objects, testimonies) that come from that real event and, in addition, the fact that it is played by the people involved in that event. In Argentina, the writer, theatre and film director and performer Lola Arias is the one who feels and recognizes herself as part of the lineage of the 2oth century's German theatre and, especially, of Weiss' theatre. This article will analyze the presence of documentary theatre in her work, but, especially, in Campo minado (2016-2020), a play that brings together three Argentine veterans and three British marines on stage to narrate and document the Malvinas War's experience and traumatic effects.
\end{abstract}

\title{
Keywords
}

political drama, documentary theater, Lola Arias, Campo minado.

¿Alguna vez mataste? ¿Alguna vez viste ahogarse a alguien en el mar helado? ¿Alguna vez fuiste a una guerra? Lola Arias, Campo minado

\section{Sobre el Teatro Político y el Teatro Documento}

Dentro de los estudios teatrales la categoría teórica denominada teatro documento se inscribe dentro de una noción más general llamada teatro político. Si bien puede considerarse que el teatro siempre es político, el concepto fue formulado por Erwin Piscator en las primeras décadas del 
siglo XX. Y aunque existe un teatro político con autores cercanos o incluso militantes de ideologías de derecha, el denominado «teatro político» fue aquel que incorporó el teatro a la lucha del proletariado por su emancipación en el marco de las revoluciones sociales de izquierda.

Piscator trasladó la teoría marxista al teatro y recogió sus ideas y experiencias en su libro Teatro Político, publicado en 1929. En la introducción, el autor señala la necesidad de fijar no solo los procesos creativos teatrales, dado que el teatro es el «arte más fugaz de todos» (1976:27) sino también, «la historia de todos sus factores y episodios, y los acontecimientos teóricos que de ellos se desprenden» (1976:27) recomendación metodológica orientada a la necesidad del «trazado de principios inequívocos» (1976:28) y a la idea de que todo proceso de creación teatral es un proceso de investigación histórica y política y no solo estética.

Al indagar sobre la genealogía del teatro político, Piscator halla un episodio fundamental a fines del siglo XIX a partir del cruce entre literatura y proletariado: ${ }^{1}$ el naturalismo como estética y, en el campo teatral, el teatro del pueblo. Según Piscator, el objetivo claramente político de este tipo de teatro es mostrar la relación entre los acontecimientos vistos en escena y las fuerzas activas en la historia. El teatro político se asume como instrumento de transformación en manos de la clase trabajadora y, por ello, su estética, su forma y características fueron aquellas que sus dramaturgos consideraron que mejor se prestaban para tal fin.

En el Capítulo VIII de su libro, Piscator desarrolla la idea de Teatro Documento a partir de una obra fundacional y una intención estética: «la primera representación cuyo único fundamento literario y escénico lo constituía el documento político fue A pesar de todo. (Grosses Schauspielhaus, 12 de julio de 1925)» (1976:75).

El drama documental es eficaz artística y políticamente porque logra una compenetración entre la acción escénica y las grandes fuerzas de virtualidad histórica. Para ello apela a episodios bien reconocibles de lucha social, a un auditorio que se identifica con tales acontecimientos porque los ha vivido, a la horizontalidad e intercambio de roles de los agentes propios de la creación teatral, al trabajo de archivo en términos de recuperación de materiales como fotografías, notas de diarios, y a la innovación técnica del cine ${ }^{2}$ o la proyección audiovisual como estrategia moderna. ${ }^{3}$

Bertolt Brecht, que inicialmente trabajó como dramaturgo para Piscator, en su escrito Pequeño organum para el teatro (1948) retoma ciertas consideraciones en torno al teatro político, al proceso de creación, a la función que le adjudica al materialismo dialéctico en el teatro, al distanciamiento crítico necesario en la instancia de expectación y a la idea de teatro épico que ya Piscator en el prefacio de su libro había explicado y justificado. Brecht crea un armazón teórico sólido que ha sido influencia para muchos directores y dramaturgos posteriores hasta hoy en día. La politicidad documental del teatro brechtiano implica la inclusión de fuentes primarias y documentos políticos reales a partir de los cuales se crea la ficción dramatizada y las puestas en escena regidas por la innovación técnica y la multiplicidad artística.

El teatro político tuvo su auge en Latinoamérica hacia mediados del siglo XX, vinculándose a los movimientos populares y a los procesos revolucionarios que exigían la urgencia del compromiso del artista con los programas políticos representativos de esos procesos. En la Argentina, el teatro popular del peronismo, el teatro del realismo reflexivo, el ciclo de teatro abierto y el de teatro por la identidad entre otros, son leídos por cierta crítica en la órbita de este concepto.

\section{Sobre teatro documento y archivo}

Expusimos, entonces, que el teatro documento o documental puede considerarse un deslinde o una deriva del teatro político al gestarse en el linde entre la ficción y la realidad y trabajar especialmente con las ideas de archivo y documento o fuente primaria. Es también en Alemania donde se 
logra protocolizar teórica y metodológicamente esta experiencia creativa sobre todo a partir del teatro y las propuestas conceptuales de Peter Weiss.

Confundido muchas veces con la denominación de docudrama o biodrama, el teatro documental pretende no ser ficcional y además estar protagonizado por los propios involucrados en el acontecimiento que se lleva a escena. Es decir, el valor documental radica en la apropiación de una historia real, en la activación semiótica de insumos teatrales (textos, fotos, proyecciones, vestuario, objetos, testimonios) que provienen de ese episodio de la realidad y, además, en que es actuado por personas que, de alguna manera, han vivido ese hecho. En tal sentido, Piscator comenta que la gran objeción que había presentado la Central del Partido ante la propuesta de A pesar de todo, era la de que esos ilustres personajes de la historia revolucionaria no podían ser representados por actores, ${ }^{4}$ exponiendo, no solo de manera general, la tensión entre realismo estético y realismo histórico sino, de manera particular dentro la teoría teatral, la de los dilemas alrededor de la noción de mímesis y de denegación dramática. ${ }^{5}$

El texto de Peter Weiss, «Notizen zum dokumentarischen Theater» («Notas sobre el Teatro documento») - publicado en 1968 en la revista Theater heute y reimpreso más tarde en el volumen de 197, Rapporte 2 (Informes, 2) - es considerado como la apuesta teórica de redefinición del concepto de teatro documental en el marco del sistema de neo-modernización de la práctica escénica. En la primera nota de las catorce que componen el texto, Weiss vincula el teatro documental a su matriz realista ${ }^{6}$ definiéndolo como 'teatro de información' ya que renuncia al principio de invención. El carácter informativo del teatro documental se sostiene en la utilización de materiales provenientes de muy variados archivos:

Expedientes, actas, cartas, cuadros estadísticos, partes de la bolsa, balances de empresas bancarias y de sociedades industriales, declaraciones gubernamentales, alocuciones, entrevistas, manifestaciones de personalidades conocidas, reportajes periodísticos y radiofónicos, fotografías, documentales cinematográficos y otros testimonios del presente constituyen la base de la representación. (Weiss, 2017:3)

A esta variedad de textos y géneros Weiss les otorga el valor de «material auténtico» de los que se sirve la escena para darles forma. Pensando desde la perspectiva de los estudios que desde la filosofía y la historia se desplegaron en torno a la noción de 'archivo', la intervención de Weiss pone el foco en dos cuestiones inherentes al concepto. La primera de ellas tiene que ver con esa marca o rasgo de autenticidad de un documento archivable frente, por ejemplo, al carácter de falsedad de un texto dramático de autor atravesado por la noción de literatura o ficción. El adjetivo contundente que Weiss emplea para caracterizar los documentos o testimonios, abre un campo denso de discusión teórica acerca del valor de lo documental, lo testimonial y verdadero. En tal sentido, Guillermo Canteros, al abordar la poca posibilidad que tiene el arte de prescindir de las funciones mediadoras de la forma, reflexiona sobre dicha tensión:

Justamente, en las experiencias que actualizan las crónicas, las etnografías del presente que interesan, el valor no reside en lo verdadero, sino en lo auténtico, y la autenticidad es la autenticidad de la forma que se opone al de la mediación representativa y al de la inmediatez de la ética (2020:132)

La segunda consideración se desprende de la expresión «darles forma» para la escena de la cita de Weiss, lo que implica atender al vasto campo de discusión alrededor de la idea de manipulación del archivo desde Derrida en adelante. Así, sobre el escenario de la lectura, se abre el telón del juego dramatúrgico ensayando nuevos sentidos sobre los bienes patrimoniales de la cultura, alterando, revirtiendo e invirtiendo lecturas que, por expansión e invención, producen otros textos en base a los 'auténticos'. El teatro se introduce sigilosamente en el archivo de las textualidades, de las historias nacionales y estéticas y de las biografías con el fin de desviar la interpretación fijada o consagrada de ese valor arcóntico y verdadero del archivo. En otras palabras, la disolución 
de los objetos-textos a través de la lectura y la abolición de una mirada esencialista e inmanentista sobre esos objetos, tiende a desfetichizarlos y liberarlos de tal modo que la escritura dramática se dibuja en un espacio vacío, el espacio de la invención o de la mediación representativa según la mirada de Canteros en la cita precedente.

El sentido construido por el archivista-dramaturgo-teatrista responde a la idea del teatro como una relación indiciaria de algo próximo pero a la vez lejano, una reposición que es trazo, vestigio o huella de algo que estaba allí (un texto, un acontecimiento histórico, una biografía) y que ha desaparecido pero que retorna de manera belicosa: «uma manifestação de horror vacui, porém, ali onde a primeira satura o sentido com referencialidade significante, esta segunda postula a transcendência como um para além daverificação» (Antelo, 2007:45). Por lo tanto, el teatro documental opera por intervención y manipulación de la noción misma de lo teatral, al desligarse y prescindir de lo puramente dramático y escénico, es decir, del valor ficcional, de la creación de una intriga dramática a partir de un conflicto ilusorio y de la interpretación actoral. Por ello es que actúa como signo, violentando las teorizaciones que desde La poética de Artistóteles en adelante, han definido al teatro. Pero tampoco podríamos vincular el teatro documento a lo propiamente historiográfico, no es la historia o la verdad de la historia y en tal sentido también opera corrosivamente sobre el discurso histórico y su proceder peculiar. La posición teórica de Weiss a través de sus notas reflexivas se desliza entre la eficacia que la escena documental arma a partir de la selección y montaje de las noticias del archivo de los medios y la potencia restringida que posee el teatro documento o, en otras palabras, su eficacia limitada comparada con el poder de transformación social que reviste toda acción política en la calle: «no puede rivalizar con el contenido de realidad de una auténtica manifestación política. Jamás alcanza el nivel de las manifestaciones dinámicas de opinión que se desarrollan en el escenario de la opinión pública» (Weiss, 2017, Nota 6); y la eficacia que la escena documental arma a partir de la selección y montaje de las noticias del archivo de los medios. El teatro documento, de manera oblicua, denuncia los intereses de los medios de información a partir de lo que Weiss establece como la crítica de encubrimiento, la crítica de falseamientos de la realidad y la crítica de mentiras:

Las noticias de prensa, radio y televisión, ¿son orientadas de acuerdo con los puntos de vista de unos grupos de intereses dominantes? ¿Qué nos escatiman? ¿A quién sirven las exclusiones? ¿A qué círculos sirven de provecho, cuando se encubren, se modifican, se idealizan determinados fenómenos sociales? (2017, Nota 2)

La posición de Weiss es oscilante porque si en la Nota 1 el autor sostiene que el teatro documento es teatro informativo, en la 7, al afirmar que el teatro documento «será un producto artístico si quiere tener el derecho a existir» (2017:5), termina circunscribiéndolo al campo y a las reglas del arte, aunque intente liberarse del ámbito estético y se desprenda de sus categorías; aunque no quiera ser nada acabado sino una simple toma de posición y una acción combativa; aunque proceda por mostración violenta e impacto en la conciencia. ${ }^{7}$ Las convenciones del proceso de creación tanto dramatúrgicas como escénicas quedan explicitadas a partir de las prescripciones metodológicas señaladas por Weiss en la Nota 12. Elaborar el material documental significa ordenar cronológicamente las noticias y fragmentos de noticias; alternar en la intriga los momentos breves, consistentes en un solo hecho con unidades más largas y complejas; describir situaciones de manera contrapuesta dando lugar a la multiplicidad de voces para contar un acontecimiento y aportar variaciones sobre un tema. Asimismo, la caricaturización, las canciones con función de reseña o comentario, la introducción de la figura del coro y la interpretación a través del uso de máscaras para generar los efectos paródicos son las convenciones o códigos de teatralidad prioritarios para el teatro documental. Con el fin de representar cómo un individuo o un grupo social es afectado por los acontecimientos, la información debe interrumpirse con reflexiones, monólogos, visiones retrospectivas, dando lugar a la manifestación de comportamientos contradictorios. 
Weiss insiste en que el objetivo del teatro documental es develar cómo una realidad interna es el efecto de respuesta a procesos externos.

\section{Una versión del teatro documental en Argentina: Lola Arias y Campo Minado}

En Argentina, quien se siente y se reconoce inscripta en el linaje del teatro alemán del siglo XX y, especialmente del de Weiss, es la escritora, directora de teatro y cine y performer Lola Arias. Según sus propias declaraciones en la entrevista realizada por Jordi Batallé en marzo de 2017 - en Radio France International a propósito del estreno de Campo Minado en París - Lola Arias caracteriza su quehacer teatral a partir de rasgos distintivos que definen una poética surgida siempre de verdaderos procesos de investigación. La investigación teatral encarada por Arias gravita alrededor de varios centros de interés: el argumental por lo vivo y real, la ambigüedad de sentido que provoca el linde entre ficción y realidad, una peculiar técnica de interpretación actoral al elegir trabajar con personas que vivieron esas historias y no con actores que hacen de otros y en la codificación escénica a partir del cruce de artes.

Mi vida después (2009), en la que seis jóvenes son convocados para reconstruir la juventud de sus padres en la década del 70 a partir de fotos, cartas, cassettes y ropa usada; Familienbande (2009) sobre la vida de una familia con dos madres; Melancolía y Manifestaciones (2012), actuada por ella misma y cuya dramaturgia surge del diario íntimo en el que va anotando las propias vivencias que experimenta ante el padecimiento psíquico de su madre; El año en que nací (2012) basada en biografías de jóvenes chilenos nacidos durante la dictadura; El arte de hacer dinero (2013) protagonizada por mendigos, músicos de la calle y prostitutas de la ciudad de Bremen; Atlas des Kommunismus (2016) estrenada en el Gorki Theater de Berlín, obra que reconstruye el derrotero socialista de la Alemania del último siglo a través de la vida de ocho mujeres vinculadas a la RDA, constituyen parte del corpus de obras resultado de sus investigaciones y experimentaciones teatrales y performáticas.

Campo minado ${ }^{8}$ fue estrenada en 2016 en el Royal Court Theatre de Londres y ese mismo año en Buenos Aires en el marco de la Temporada Internacional Reino Unido del Teatro San Martín. ${ }^{9}$ Como proyecto de teatro documental, halla su antecedente en la invitación que la autora recibe de un festival internacional en Londres en el año 2013 con el fin de conmemorar el centenario de la Primera Guerra Mundial. En respuesta a dicha invitación, Lola Arias decidió trabajar sobre la guerra de Malvinas y para ello convocó a cinco veteranos argentinos quienes narraron sus recuerdos utilizando diversas estrategias discursivas y teatrales. La obra para el festival internacional de Londres fue el inicio de Campo minado, porque desde allí se instala para la autora la necesidad de investigar sobre tal acontecimiento bélico a partir de lo que prejuzga como hipótesis, es decir, la vivencia no traumática en los combatientes del bando inglés, prejuicio y argumento ${ }^{10}$ que queda absolutamente invalidado, como queda demostrado en la obra que escribe y dirige.

El proceso creativo de Campo minado duró dos años entre las audiciones llevadas a cabo en Inglaterra y en Argentina para encontrar a los protagonistas. Una vez seleccionados los excombatientes-actores, se implementaron durante tres meses encuentros para el trabajo de mesa y ensayos, proceso centrado exclusivamente en escuchar los relatos biográficos de cada uno de ellos a partir de los cuales se fue armando el texto y las secuencias de la intriga dramática. Tres veteranos argentinos, dos militares ingleses de rango y Sukrim, un Gurka, son los actores que desde el preámbulo de la obra rompen con la ilusión teatral al informar sobre la naturaleza del proyecto artístico. Es interesante señalar que la potencia que adquiere la narración autobiográfica de los hechos traumáticos de la guerra desvanece rápidamente la categoría de 'enemigo' con que 
el discurso historiográfico definió a los combatientes argentinos e ingleses. El teatro propicia el acercamiento de esos hombres y sus historias particulares y es la ocasión para empatizar entre ellos de manera tal que el enemigo deviene en amigo y cómplice artístico.

Desde el punto de vista de la representación, la acción se desarrolla prioritariamente en el centro del escenario iluminado donde se llevan adelante los monólogos y diálogos de los personajes. En el espacio central se ubica una pantalla donde se proyectan audiovisuales reales de época, sobre todo de noticieros y programas especiales con el tema de la guerra y una plataforma mínimamente elevada que es ocupada en distintos momentos de la acción por la banda de rock, integrada por los actores que interpretan clásicos del rock inglés y creaciones colectivas. En los laterales del escenario, iluminados profusamente, se ubican los dos bandos con sus escenografías propias vinculadas a lo nacional: banderas, vestuarios, mapas, prensa, fotos, epistolarios.

La obra bilingüe se estructura en capítulos o escenas cuyos títulos ${ }^{11}$ se proyectan en la pantalla y permiten ir siguiendo la secuenciación narrativa de los relatos autobiográficos, de los diálogos y del montaje de las escenas satíricas referidas al contexto social e histórico y político.

«Audiciones» es el título del primer acto o capítulo proyectado en inglés y en español. La escena repone la reclusión real de los soldados y el interrogatorio típicamente militar para identificarlos. Pero a su vez, irónicamente funciona como la presentación de los actores que 'audicionan' para la obra: nombre, edad, rango, rol en la guerra, ocupación actual y otros datos personales son necesarios para explicar quiénes son en el presente de la acción dramática y quiénes eran al momento de la guerra.

La escenografía diseña una arquitectura sencilla, análoga a la de un libro abierto que se eleva en el centro del escenario. Allí se sucede la proyección de la información dramática propia del teatro documental: datos históricos sobre la guerra de Malvinas y los antecedentes de ocupación del territorio, las biografías de los actores-excombatientes, la dificultad lingüística para entenderse entre ellos y referencias constantes el proceso de creación teatral.

Los microrrelatos dramáticos informan acerca de los distintos métodos de reclusión y formación tanto argentino como inglés, es decir, sobre la «colimba argentina» y las vivencias del servicio militar obligatorio y sobre los violentos entrenamientos de los marines ingleses. Pero también interviene el discurso de la historia al narrarse el contexto de la dictadura militar y los antecedentes bélicos asociados a los conflictos políticos tanto de Argentina como de Inglaterra: por un lado, la guerra contra Chile y el terrorismo de Estado; por otro, la Guerra Fría, la revuelta de Irlanda del Norte y el terrorismo del Ira en el Reino Unido.

Campo minado exhibe no solo los archivos personales de cada uno de los excombatientes/actores integrados por cartas, ropa de época, objetos guardados como reliquias y restos de materiales atesorados como registros de la experiencia traumática, también despliega una selección de información mediática, por ejemplo, la revista Gente, los diarios anunciando la visita del papa a la Argentina, las crónicas e imágenes captadas por los reporteros gráficos de guerra. Muchas de esas imágenes se actualizan en la escena por auto-re-conocimiento de sus protagonistas de manera tal que la ficción dramática a medida que presenta la información de los documentos auténticos como dice Weiss, opera por disolución tanto de categorías históricas como de representaciones e imaginarios sociales. Los bandos enemigos que dichos documentos fijan en el archivo político y militar de las naciones o en el teatro de las operaciones bélicas del territorio austral, en la escena dramática son reinterpretados proponiendo una alianza amistosa y artística para narrar la experiencia humana devastadora que implica toda guerra.

«Camino a la guerra» se abre con el despliegue de las banderas nacionales a las que se asocia, por un lado, la narración del viaje de los soldados ingleses, sus rutinas diarias en los barcos y la declaración de guerra de Margaret Thatcher, pronunciada el 3 de abril de 1982 ante la Cámara de los Comunes. Por otro lado, la llegada de los soldados argentinos a las islas y el discurso de Galtieri anunciando el desembarco y la toma en una Plaza de Mayo colmada de ignorante nacionalismo. A partir de allí, los microrrelatos teatralizan los sucesos trágicos como el hundimiento del crucero 
General Belgrano, los ataques de la aviación argentina en Monte Harriet, la violencia real y simbólica que sufrieron los combatientes tanto en las islas como al regreso a sus propios países, hasta los efectos postraumáticos de la guerra en la intimidad del hogar como el caso de la narración de intento de suicidio de Marcelo Vallejo.

Asimismo, estas escenas altamente dramáticas se interrumpen con otras humorísticas e irónicas cuya función es la de deconstruir representaciones sumamente esclerosadas y consolidadas puestas a circular por la discursividad política. La entonación del famoso slogan publicitario de la marcha «Argentinos, argentinos vamos a vencer»; la proyección de la campaña de recolección solidaria transmitida por televisión durante 24 horas en ayuda a los soldados argentinos; la teatralización del mito salvaje y antropofágico alrededor del Gurka, ${ }^{12}$ la escena del travestismo erótico del marine inglés y las canciones en vivo de la banda de rock provocan un cambio de ritmo, un desvío de la intención dramática que modalizan la tragicidad.

La obra articula el pasado histórico del suceso bélico con el pasado de la posguerra, por ejemplo, el regreso de los soldados argentinos a Malvinas después de 25 años y también con el presente como queda explicitada en la pregunta acerca de «¿Dónde están los muertos británicos de la guerra en esta obra?» que apunta directamente a reflexionar sobre cómo ha resuelto el Reino Unido la historización de tal acontecimiento. Los cruces temporales y la constante articulación de pasados y presente orienta la lectura hacia perspectivas teóricas vinculadas con la implementación de las políticas de la memoria, de las reparaciones históricas y del valor testimonial de protagonistas y testigos.

Campo minado trabaja con materiales provenientes de archivos históricos y personales, pero opera violentamente con ellos. La violencia o manipulación ejercida en el archivo que desvía los documentos de la historia hacia la potencia de la ficción o discursividad estética se deja ver en el montaje de la historia nacional y colectiva con la historia individual de cada uno de ellos, en el uso de la técnica y lo multiartístico como signo escénico, en la narración contada por los cuerpos protagonistas que se mueven, visten y desvisten, cantan, hablan en su lengua e interactúan intercambiando roles dentro de una semiosis gestual muchas veces cómica e irónica. La información, puesta en relación, detenida en el detalle, exaltada en su contradicción, revelada también como silencio u omisión, corroe la idea de lo verdadero, lo real y lo auténtico del hecho histórico. El teatro documental ancla lo escénico dentro de una lógica de la presentación y de la autorreferencialidad más que en sistemas representacionales y miméticos, desestabilizando el discurso histórico por un uso de la información que es desviada o extraviada de sus contextos, como lo expresa Weiss:

Los oradores individuales se enfrentan a una serie de portavoces. La composición consiste en fragmentos antitéticos en series de ejemplos análogos, en formas contrastantes, en proporciones cambiantes, en campos de fuerza. Variaciones sobre un tema. Desarrollo gradual de un proceso. Interferencia de alteraciones, disonancias. (2017: 5, Nota 12)

Es muy llamativo, teniendo en cuenta esto último, lo que comenta Lola Arias acerca del contexto de producción de la obra que, si bien fue financiada por la colaboración de seis festivales internacionales, no halló en principio, ninguna institución argentina que avalara y apoyara el proyecto teatral. La gran razón de esta negativa tiene justamente que ver con la no interferencia ni la alteración del sentido histórico: el reclamo de soberanía argentina sobre las islas, reclamo permanente que también es teatralizado en la obra a través de las posiciones que cada uno adopta. Lo que muestra este teatro documental es que la guerra de Malvinas si bien es su tema no es su fundamento, posición declarada por la propia la autora y directora:

El proyecto partía de una base: para todo el mundo era un proyecto imposible. El supuesto también era que llevar una obra así a escena, con las voces de los dos bandos, con la alianza y la colaboración de los veteranos y los marines ingleses, implicaba abandonar el reclamo de soberanía, implicaba una traición a la patria, como si yo estuviera firmando un pacto con el diablo. (Arias, 2017) 
El sentido final no gravita sobre la soberanía de las islas, no importa la guerra de Malvinas porque la obra es sobre las personas, es sobre qué es ser un veterano, qué aconteció en el pasado y qué acontece en el presente de quienes fueron a la guerra, a cualquier guerra y sobrevivieron:

Lo que me sorprendió no fue tanto la crueldad del relato bélico ya que uno está habitado por esas imágenes del mundo (matanzas, cuerpos desposeídos) lo que más me conmocionó fue cómo esa experiencia define quién va a ser uno. No es una guerra de dimensiones colosales sin embargo lo que más me sorprendió es lo que la guerra te hace. (Arias, 2017)

En función de este proceso creador y su resultado es interesante comprobar cómo se reversionan tanto la concepción pionera de Piscator acerca del teatro político y su función revolucionaria para la asunción de una conciencia social como la de ciertas aseveraciones de Weiss alrededor de la eficacia de un teatro que documente artísticamente. Aquí, lo político se inscribe en las subjetividades y en las posiciones individuales que se deshacen y se refundan a la vez.

Finalmente, la revolución que propicia es una revolución humana en términos de reflexión sobre la conciencia desprovista de propaganda política o de doctrina ideológica de los usos de la memoria. La escena de la sesión de terapia donde analizado y analista (inglés y argentino) intercambian sus roles teatraliza, no solo el síntoma traumático conjurado por la narración (el intento de suicidio, la exposición del diario íntimo, los efectos posbélicos en ambos) sino también las razones cuasi terapéuticas que influyeron para que los seis aceptaran la propuesta del proyecto teatral de Lola Arias.

La superposición de las voces que en inglés y en español enuncian la historia de la guerra («Si quieren saber más está la versión en inglés y en español en Wikipedia») tanto como la «danza del kukri», el regreso de Sukrim a Malasia y la lectura del poema tradicional malayo en la lengua original con que finaliza la obra son las manifestaciones y concreciones estéticas de la confianza que Peter Weiss depositaba en los procesos creativos alrededor del teatro documental, como queda expresado en su nota final:

Por ello el Teatro Documento se enfrenta a la dramática que tiene como tema capital su propia desesperación y su rabia y que se aferra a la concepción de un mundo absurdo y sin salida. El Teatro-Documento aboga por la alternativa de que la realidad, por impenetrable que se haga a sí misma, puede ser explicada en todos sus detalles (2017:7, Nota 14).

\section{Referencias}

Antelo, Raúl (2007). O arquivo e o presente. Gragoatá (22), 43-61.

Antelo, Raúl (2011). «A coleção, o objeto e o estado gel do intercâmbio» en Crespi, Marcela (2011) «Raúl Antelo: las afinididades electivas» en Entrevero de piernas y alambres,http://maxicrespi.blogspot.com/

Antelo, Raúl (2012). A iminência e o arquivo do futuro. Seminário da $30 a$ edição da Bienal de São Paulo, noviembre.

Arias, Lola (2017). Entrevista realizada por Jordi Batallé para Radio France Internationale. https://www.youtube.com/watch?v=JmGzdqCMq30

Arias, Lola (2020). Campo minado. https://www.youtube.com/ watch?v=fgKDsuevQZM

Arpes, Marcela (2013). La escritura dramática como archivo. En Actas V Jornadas Nacionales de Investigación y Crítica teatral. AINCRIT.

Arpes, Marcela (2015). De la lectura de la tradición a la dramaturgia salvaje para un teatro nacional actual. Actas IX Congreso Internacional Orbis Ter- 
tius de Teoría y Crítica Literaria.http://www.memoria.fahce.unlp.edu.ar/ trab_eventos/ev.8611/ev.8611.pdf

Badiou, A. (2005). Imágenes y palabras: escritos sobre cine y teatro, Buenos Aires, Manantial

Brecht, B. (1948) Pequeño organum para el teatro, Madrid, Ed. Don Quijote. Traducción Christa y José María Carandell.

Canteros, Guillermo (2020). Formas del disenso/formas del consumo: reconfiguración(es) del documentalismo en la narrativa latinoamericana contemporánea. En Nicola, Mariné y Carril, Alejandra (comp.) (2020), II Simposio Internacional: América Latina y sus bordes interculturales: literatura, imaginarios, estética y cultura. Universidad Nacional del Litoral.

Irazabal, F. (2004). El giro político. Una introducción al teatro político en el marco de las teorías débiles (debilitadas), Buenos Aires, Biblos.

Pavis, Patrice (1998). Diccionario de teatro. Paidós.

Piscator, Erwin (1976). El teatro político. Ayuso.

Verzero, L. (2017) "Representaciones afectivas/efectivas en Lola Arias: "la memoria también puede funcionar como un campo minado" en Revista Conjunto, 185, 10-2017, 32-41.

Weiss, Peter (2017). Notas sobre el teatro documento. Revista Conjunto. Documento, testimonio y autorreferencia, 185. http://www.casadelasamericas.org/publicaciones/revistaconjunto/185/revista

\section{Notas}

1. El capítulo III se dedica a pensar una categoría específica que es el Teatro del proletariado surgido entre 1920 y 1921. Esta noción implica no solo la existencia de autores propios, sino un proceder creativo específico vinculado a la función revolucionaria que afecta tanto a la dramaturgia como a la teatralidad y hasta a la interpretación actoral.

2. «En A pesar de todo también la película era documento. Utilizamos, ante todo, fotografías auténticas de la guerra, de la desmovilización, de un desfile de todas las casas reinantes de Europa, etc., procedentes del material del archivo del Reich, que fue puesto a nuestra disposición por unos amigos. Las fotografías mostraban descarnadamente la atrocidad de la guerra» (1976:79).

3. Para el caso de A pesar de todo, la proyección, simultánea a la actuación escénica, es el film Banderas.

4. «Gasbarra propuso destacar un trozo de nuestro proyecto, a saber: la época que abarcaba desde el estallido de la guerra hasta el asesinato de Liebknecht y Rosa Luxemburgo, y hacer de él una revista independiente. Para expresar que la revolución social, aun después de aquella terrible derrota de 1919, sigue su avance, la titulamos con las palabras de Liebknecht: A pesar de todo. Al exponer este proyecto en la sesión decisiva de la Central, los delegados del partido sacudieron recelosamente la cabeza al pensar que personajes como Liebknecht y Rosa Lux emburgo iban a ser representados por actores. A muchos les pareció también peligrosa la intención de poner en escena a miembros del gobierno, como Ebert, Nosle, Scheidemann, Landsberg, etc.» (1976:76).

5. Una de las implicancias del concepto de denegación teatral es justamente el juego que se establece en el escenario entre «el efecto de realidad» y «el efecto teatral» en una permanente oscilación, provocando identificación y distanciamiento (Ver Pavis, 1998: 121-122).

6. Weiss establece los antecedentes y las homologaciones que adquiere en su presente el teatro documental vinculado al realismo: «El teatro realista de nuestro tiempo, que, desde el movimiento del Proletkult, el Agitprop, los experimentos de Piscator y las piezas didácticas de Brecht, ha adoptado numerosas formas, puede encontrarse actualmente bajo denominaciones diversas, como Teatro Político, TeatroDocumento, Teatro de Protesta, Antiteatro, etc. Partiendo de la dificultad de hallar una clasificación para las variadas formas con que se expresa esta dramática, intentaremos aquí tratar una de sus variantes, la que se ocupa exclusivamente de 
la documentación de un tema, y por ello puede ser llamada Teatro-Documento» (Weiss, 2017:3).

7. Nota 12: «No hay un ritmo calculado, sino material en bruto, compacto o en fluir libre, en la descripción de lucha social, en la exposición de una situación revolucionaria, en la información sobre un escenario bélico. Intervención de la violencia en el choque de fuerzas» (Weiss, 2017:5).

8. Ficha técnica: Escrita y dirigida: Lola Arias - Actores: Lou Armour, David Jackson, Gabriel Sagastume, Rubén Otero, Sukrim Rai, Marcelo Vallejo - Investigación y Producción: Sofía Medici, Luz Algranti - Escenografía: Mariana Tirantte - Música: Ulises Conti - Diseño de luces y Dirección técnica: David Seldes - Video: Martín Borini - Ingeniero de sonido: Roberto Pellegrino, Ernesto Fara - Vestuario: Andy Piffer - Asistencia de dirección: Erika Teichert - Asistencia producción: Lucila Piffer - Asistencia técnica y de producción: Imanol Lopez - Asistente de vestuario: Federico Castellón Arrieta - Asistencia de investigación UK: Kate O'Connor.

9. En el marco de la pandemia, el 3 de abril del 2020 se pudo ver a través de Youtube el contenido liberado de aquella breve temporada en Buenos Aires, proyección organizada por Buenos Aires Cultura en Casa - Complejo Teatral de Buenos Aires Fundación amigos del Teatro San Martin y la Universidad Nacional de San Martín.

10. En la entrevista citada, Lola Arias refiere un dato histórico evidente asociado a las diferencias materiales de los bandos intervinientes en el acontecimiento bélico y a la profesionalización del ejército inglés frente a soldados jóvenes, civiles y con mínima instrucción militar de los combatientes argentinos.

11. Los títulos de las escenas son: 1) Audiciones - Auditions; 2 ) Convertirse en soldado (del lado del escenario argentino se proyecta en inglés, del lado derecho, el inglés, se proyecta en español); 3) Diario de guerra; 4) Camino a la guerra (del espacio del bando argentino se proyecta la imagen de Margaret Thatcher, del inglés, la de Galtieri); 5) La espera (organizada en subcapítulos o escenas: El hundimiento del Belgrano, Monte Harriet, 6) Después de la guerra; 7) Ayer y hoy (organizada en subcapítulos o escenas: Malvinas / Falklands.

12. La escena en formato de reality show en la que participan Marcelo Vallejo, soldado argentino, y Surkim, el gurka, teatraliza de manera muy irónica las intervenciones de este último en la guerra, contradiciendo esa mitología de las orejas cortadas y comidas, narración que finaliza con el regalo de una canción típica nepalesa que el gurka ofrece al soldado argentino. 